\title{
Periferia como locus de resistência: Anticolonialismo epistêmico como horizontes utópicos
}

FERNANDES, Estevão Rafael ${ }^{1}$

\section{RESUMO}

Este texto busca apresentar algumas considerações sobre resistência epistêmica, a partir da minha experiência de pesquisa sobre queer indígena. Mais do que "sexualidade", o tema diz respeito a uma ampliação necessária dos limites impostos pela colonização do olhar dentro da academia, sendo este texto um manifesto no sentido de chamar a atenção para a necessidade de novos horizontes epistemopolíticos, como contraponto a lugares de enunciação estáveis e centrados.

Colonialismo. Queer indígena. Epistemologia. Saber.

Periphery as locus of resistance:

Epistemic anticolonialism as utopian horizons

\begin{abstract}
This text seeks to present some considerations about epistemic resistance, based on my research experience on indigenous queer. More than "sexuality", the theme is about a necessary extension of the limits imposed by the colonization of the look within the academy, and this text is a manifesto in order to draw attention to the need for new epistemopolitical horizons as a counterpoint to places of stable and focused.
\end{abstract}

Colonialism. Indigenous Queer. Epistemology. Knowledge.

\section{INTRODUÇÃO}

Mais que nunca certas questões, sobretudo aquelas vistas como malditas ou cujo não-dizer é algo paulatinamente buscado por determinados setores da sociedade, nos servem para pensar como operam dispositivos de poder e mecanismos estruturais e históricos. Foucault já nos ensina, em sua História da Sexualidade, como não devemos fazer oposição entre o dizer e o não dizer, dado que há diversas formas de não dizer ${ }^{2}$. A palavra maldita da vez é sexo. A questão aqui é, em alguma medida, buscar entender o porquê disso,

\footnotetext{
${ }^{1}$ Professor de Antropologia na Universidade Federal de Rondônia. Mestre em Antropologia (UnB, 2005) e Doutor em Ciências Sociais/Estudos Comparados sobre as Américas (UnB, 2015). Autor de Existe índio gay (Prismas, 2017) e Gay indians in Brazil (Springer, 2017). Email: estevaofernandes@gmail.com.

${ }^{2}$ Foucault, 2011, p. 33.
} 
Periferia como locus de resistência:

e o farei de forma mais ou menos despretensiosa, muito mais buscando trazer algumas questões, ao meu ver relevantes, do que buscando encerrar pontos específicos.

Recuperando o que foi dito acima, do que se tratam essas questões não ditas, não discutidas, não pensadas porque pensadas em outros termos, ditadas por outras pessoas, em outros contextos para outros contextos?

Tenho dito, sempre que posso ${ }^{3}$, que a discussão sobre colonização deve fazer frente às múltiplas formas de colonização cotidianas, às diversas técnicas e instrumentos desde os quais não se diz, não se fala, não se ouve, e se apagam os silenciamentos em sua multiplicidade, pois assim como silêncio é algo que vem no plural, violências, dominações e apagamentos se dão no plural e de forma singular, a fim de apagar o diferente, tornando sua desigualdade algo naturalizado.

Os não ditos são sempre encerrados na velha fórmula que a tantos deve assustar: "é cultural", como que por essência, pronta e acabada. Como antropólogo desaprendi a compreender o que é cultura, tornando mesmo os múltiplos contextos em que tal fórmula é constantemente repetida em algo político. Tudo o que é cultural é político. Tudo o que é social é político. Tudo o que é natural, desnatural, antinatural, sobrenatural: são categorias políticas. A questão, dizia Humpty Dumpty à Alice em Alice através do Espelho ${ }^{4}$, é descobrir quem manda... e, quem manda quando se trata de colonizações, no plural? É disso que pretendo falar aqui, sobre processos de silenciamento.

O colonialismo, como eu dizia, é um processo - ainda vivo e pulsante, veremos isso adiante - tem um duplo pressuposto. $O$ primeiro é o de reduzir 0 colonizado a uma nota de rodapé de sua própria história. O segundo é o de incutir no colonizado a ideia de que sua própria colonização, apagamento e subalternização são um favor ao colonizado: libertá-lo da condição de ser o que é, para torna-lo num simulacro, num não ser preso a um não lugar é do que se trata a colonização. Façamos aqui um parêntesis.

Há alguns anos venho me dedicado a trabalhar com um fenômeno mais ou menos conhecido, de forma genérica, como "Homossexualidade indígena" (Fernandes, op cit). A escolha do termo não se dá por acaso, e, que tremam aqueles que - várias vezes até bem-intencionados - me acusaram e acusam de ser etnocêntrico, uso essa categoria - "indígena homossexual" - como lugar de enunciação político. Xs indígenas que se percebem como gays, lésbicas, trans,... em geral, se veem assim em um contexto no qual a heternormatividade já foi ensinada e gradualmente imposta em suas aldeias, vidas, seres e corpos. De que forma isso opera? Digo que a homofobia chegou aqui de caravela, e que a heteronormatividade compulsória foi - e é - uma das técnicas do

\footnotetext{
${ }^{3}$ Cf Fernandes, 2017.

${ }^{4}$ Carroll, 2012.
} 
colonialismo: a submissão do desejo do outro ao meu, colonizado, é parte do processo colonial. E, sem dúvida, ser o sujeito do próprio desejo é uma atitude anticolonial. Como isso opera?

Não podemos pensar - e a nós, que vivemos, moramos e pensamos nas, das e para as fronteiras e bordas dos eixos pelos quais o conhecimento "legítimo" é construído, constituído, consolidado e reproduzido - que o colonialismo seja uma mera abstração, ou um conceito utilizado aqui ou ali por intelectuais palestinos, indianos, europeus, americanos, quase sempre pautados e calcados em pensadores da moda e articulados como que para abençoar as discussões desenvolvidas neste ou naquele campo ou - prestem atenção - disciplina.

Se não é uma mera abstração, como o colonialismo impôs aos povos indígenas seu modelo de moral, desejo e sexualidade? De várias formas: a primeira delas foi enquadrando ${ }^{5}$ a sexualidade indígena em suas várias formas - o que os jesuítas chamavam de sodomia, a poligamia, o casamento entre parentes, etc. - com diversas outras práticas como a nudez, antropofagia e o politeísmo, por exemplo. As cartas jesuítas são repletas de trechos nas quais eles se referiam às aldeias tupinambás da costa brasileira como visões do inferno, com cheiros e sensações dignas de satanás. Falamos de um contexto no qual tudo era utilizado para transformar aquelas nações em súditos bemcomportados da coroa: bons cristãos, monogâmicos, obedientes e que só copulariam para reproduzirem - gerando pequenos súditos tão comportados e ciosos, moralmente, quanto eles.

Há duas coisas que esquecemos, porque não nos foram lembrados nas aulas de história. A primeira é o padroado: uma instituição na qual igreja e coroa se confundiam, e a partir da qual a coroa de Portugal se comprometia a converter as terras descobertas e, como contrapartida, a Igreja viria a reconhecer aqueles territórios como lusitanos. Não à toa, a primeira bandeira a tremular em território hoje brasileiro foi a bandeira da cruz da ordem de cristo. A segunda coisa que nos devemos lembrar é que o próprio conceito de Sodomia para se referir às práticas sexuais entre pessoas do mesmo sexo apenas surge no século XI, juntamente com expressões como bestialismo - e masturbação - para se referir a uma ideia de que a cada pecado equivale uma retribuição divina. Pecado e obediência é, sabemos ainda hoje, o binômio por trás da lógica e da justificativa para demonizar, literalmente, as práticas homodesejantes. Contudo, na época em que falamos em consolidação dos Estados Ibéricos, a ideia de "sodomia" foi incorporada pela coroa como crime de lesa-majestade, passível de morte, pois se uma pessoa pecasse contra Deus, toda a Sua ira recairia sobre o reino. Tinha-se, assim, uma excelente justificativa para o policiamento da vida pessoal dos seus súditos. Caso um

\footnotetext{
${ }^{5}$ Sobre o conceito de "Enquadramento" bem como para uma perspectiva mais detalhada do argumento apresentado, cf. Fernandes, 2015.
} 
fizesse algo que desagradasse à Deus (leia-se, à Igreja barra Coroa), a punição imediata era exigida para o bem de todos.

Claro que, em tempos de cura gay (sic) e ideologia do gênero (sic, de novo...), de censura às formas de criatividade e de pensamento, não podemos dizer que essas práticas tenham chegado a um termo. Esse policiamento ostensivo é uma forma de se afirmar "quem manda" - recuperaremos este ponto mais a frente.

Aliás, fazer uma crítica aos processos históricos e às técnicas e dispositivos de heternormatização é, também, fazer uma crítica à academia. Se a homofobia nasce no seio da igreja, ela aumenta e se consolida na academia, juntamente com o racismo. A nuvem discursiva desde a qual o indígena não seria apto ao trabalho, fato "cientificamente comprovado" na exposição antropológica brasileira de 1882 é a mesma que comprovará, também cientificamente, que a sífilis é um mal negro e que avós tuberculosos podem passar "degenerescência" para seus netos, como os bons juristas brasileiros falavam já no século XX. A pederastia era um mal a ser expurgado das aldeias, para o bem da nação que se buscava consolidar e construir.

Caberiam aos indígenas serem não mais bons súditos, mas bons cidadãos, de família, pagadores de impostos, subempregados, exploráveis... Quando um indígena nasce com determinada genitália, a ele será dado um nome de menino ou de menina, trabalhos de homem ou de mulher, roupa de homem ou de mulher, corte de cabelo de homem ou de mulher,... mas não qualquer homem ou mulher: de homem ou mulher não indígenas. Não se trata apenas de violentá-los em sua sexualidade, mas também em sua indianidade. Daí a acusação - contraditória mas ainda frequente, de que indígenas fora do padrão hetero imposto pela colonização seriam menos indígenas do que os indígenas bons cristãos e pais de família.

Suponho que várias dessas questões não se restrinjam apenas aos povos indígenas. A mesma nuvem discursiva que Ihes impôs determinado padrão de sexualidade segue firme e forte. A questão, como dissemos antes, "é quem manda". Falar em sexualidade indígena incomoda porque deixa claro como moral e poder caminham juntos, muitas vezes com a participação e conivência silenciosa de cientistas e religiosos bem-intencionados. Meu esforço, assim - e é esse esforço que espero compartilhar com vocês - não é mais tentar entender "a" homossexualidade indígena como fenômeno, mas o que podemos compreender a partir dela.

Ela me ensina, ao problematiza-la, que o colonialismo ainda existe e persiste. Que nossos aparatos discursivo e epistêmico são insuficientes. Que a mera reprodução de categorias acadêmicas importadas dos grandes centros e difusão do conhecimento servem como ponto de partida, mas não devemos nos deixar colonizar, limitar e disciplinar por elas. Que às vezes os pontos obscuros são mais interessantes do que a mera reprodução do que é tantas 
vezes dito. Que as fronteiras oferecem um excelente ponto de partida e que estar nas periferias é um ato político.

Mais que isso. Resistir ao discurso da moral não é se insurgir como uma religião, mas contra um aparato de poder que opera pelo apagamento. Que a gênese da censura, dos silenciamentos, da intolerância está na gênese do próprio modelo de Estado e imbuído no espírito de cada auto-proclamado "cidadão de bem" e paneleiro de plantão. Ou será que as coxinhas verdes e amarelas sabem que o losango na bandeira brasileira significava, para os positivistas, os quatro papéis que cabe à mulher ocupar em casa (mãe, filha, irmã e esposa?). Nossa República, positivista, é também misógina e efeminóbica.

Neste sentido, o queer oferece um lugar de resistência, mas para isso temos que deixar de aprender que nosso lugar é errado, que moramos longe, que nosso sotaque é "engraçadinho" ou "bonitinho", que nossa cor é escura demais e nossa sexualidade, errada; que na minha cidade não tem onças passando e que temos mais a oferecer do que mão de obra, carnaval, fotos nas praias e florestas ou locais onde usinas possam ser construídas ${ }^{6}$.

O que podemos aprender, por exemplo, desde textos queer africanos, do pensamento feminista indiano, das críticas two-spirit? Em que medida a reprodução de um conjunto de autorxs - quase sempre situados na França ou na Califórnia - nos permitem contrapor de forma radical movimentos de direita que insistem em chamar a educação para a diversidade sexual de "ideologia de gênero"? Até que ponto se pode levar adiante uma empreitada deste tipo sem levar em consideração o papel de igrejas neopentecostais no interior do Brasil? É possível, por exemplo, compreender os casos de agressão motivados por religião no País sem levar em conta a forma como a homofobia tem se naturalizado em comentários de portais de notícias e redes sociais?

Além disso, é necessária uma agenda de superação da divisão de trabalho acadêmico no Brasil, desde a qual os centros (localizados no centrosul) fornecem teoria - quase sempre reproduzindo autores dos Centros (localizados no norte epistêmico), enquanto ao "resto", cabe fornecer "experiências".

O que movimentos feministas ou LGBT na Amazônia ou no campo, por exemplo, podem nos dizer sobre garimpo, desenvolvimento, PAC, grandes obras, exploração sexual nas fronteiras do capitalismo brasileiro - e viceversa? É possível recuperar a voz desses atores sem filtrá-la em nossa prática acadêmica, neutra, objetiva, externa, e, no fim das contas, morna? Narrar simplesmente suas trajetórias para corroborar a hipótese pensada por algum autor pop, como se nosso contexto fosse o de um café às margens do Sena ou em Nova lorque, e não de um pós-golpe institucional branco e heteropratriarcal

\footnotetext{
${ }^{6}$ Nesse sentido, conferir o conceito de "queer caboclo", apontado em Fernandes e Gontijo, 2016.
} 
é, em última instância, o de cumplicidade com o status quo e com a estrutura de poder que lhe é subjacente.

De fato, penso que essas questões tragam relação direta com este dossiê da interritórios. Aos leitores mais incautos, talvez isso não tenha ficado suficientemente claro, mas ao trazermos aqui o queer indígena como estratégia anticolonial buscamos afirmar ser impossível pensar a divisão do trabalho acadêmico, as caixas epistêmicas às quais estamos restritos nas tradicionais separação de departamentos nas universidades, na forma como encapsulamos as diferenças em conceitos muito bem amarrados desde que escritos em francês ou inglês... Não há sublevação sem que essas estruturas sejam permanentemente enfrentadas.

Ao dizermos que, no fim das contas, o que está me disputa é "quem manda", assim o fazemos justamente por termos em mente que a grande batalha, hoje, é travada no campo da legitimidade discursiva. O que está em jogo é a legitimidade do lugar de enunciação de quem fala, mais até do que "o que" está sendo dito. Enquanto nos mantivermos atrelados à lógica desde a qual nós, como indígenas, amazônicxs, sertanejxs, latinos, quilombolas, queer, mulheres, negrxs, faveladxs, caipiras,..., não somos sujeitos produtores ativa $e$ continuamente de epistemopolíticas radicais, seguiremos mantendo uma ordem discursiva bem-?comportada e compartimentalizada na e para a academia e para a manutenção do status quo. Quando, por exemplo, governos populistas latino-americanos acusam setores progressistas de serem "comunistas" ou nossas escolas e universidade de serem centros de irradiação "ideológica", na prática, o que se está buscando fazer é retirar desses espaços a legitimidade na produção de discursos críticos a essa manutenção da ordem. Convenhamos, não é preciso ser comunista para ser queer, ou latinx, ou para buscar radicalidades-outras a partir das quais uma utopia seja possível.

O problema - ou um deles - é que uma nova geração aprendeu a temer o comunismo. Talvez seja hora de as novas gerações terem o mesmo pavor de vários outros regimes discursivos alternativos, como o feminismo negro ou as críticas anticoloniais indígenas. É chegado o momento de tais universos, até então relegados às periferias ou à condição de objetos passarem a figurar, ainda mais, como referenciais para além de teóricos, mas políticos e metodológicos, a fim de ampliar, mesmo, nossa própria visão tradicional - e sem graça - de uma contraposição epistêmica.

\section{REFERÊNCIAS}

CARROLL, Lewis. Alice através do Espelho. Rio de Janeiro: Salamandra, 2012.

FERNANDES, Estevão R. Decolonizando sexualidades: enquadramentos coloniais e homossexualidade indígena no Brasil e nos Estados Unidos. Tese (Doutorado em Ciências Sociais). Universidade de Brasília, Brasília, 2015. 
Periferia como locus de resistência: Anticolonialismo epistêmico como horizontes utópicos

FERNANDES, Estevão, R. Existe índio gay? A colonização das sexualidades indígenas no Brasil. Curitiba: Prismas, 2017.

FERNANDES, Estevão Rafael; GONTIJO, Fabiano. "Diversidade sexual e de gênero e novos descentramentos: um manifesto queer caboclo". Amazônica: Revista de Antropologia, v. 8, p. 14-22, 2016.

FOUCAULT, Michel. História da sexualidade I: A vontade do saber. Rio de Janeiro: Edições Graal. 2011. 